\title{
К ВОПРОСУ О ДОСТАТОЧНОСТИ КАПИТАЛА КРЕДИТНОЙ ОРГАНИЗАЦИИ
}

\begin{abstract}
АНнОтАЦИЯ. В течение последних десятилетий проблема устойчивости банковской системы приобретает международный характер, что обусловлено интеграцией банковского дела. Банкротства и финансовые трудности в ряде стран из-за недооценки рисков банковской деятельности, в том числе кредитного риска, заставили представителей международного банковского надзора и Базельский комитет подготовить директивы о достаточности капитала. В статье рассматриваются подходы органов банковского надзора и Базельского комитета к изменению составляющих статей банковского капитала и структуре весов риска, осуществления кредитной организации активных операций. Описан международный опыт определения достаточности капитала кредитных организаций. Обобщается российская практика оценки достаточности капитала Банком России начиная с 1991 г. и по настоящее время. Анализируется динамика собственных средств (капитала) кредитных организаций Российской Федерации, и отмечается снижение темпов прироста капитала кредитных организаций и норматива достаточности капитала. Делается акцент на необходимость снижения рисков активных операций кредитных организаций для выполнения норматива достаточности капитала.
\end{abstract}

кЛючЕВыЕ слОВА. Собственные средства (капитал) кредитной организации; достаточность капитала; Базельский комитет; активы, взвешенные с учетом рисков банковской деятельности.

ИНФОРМАЦИЯ О СТАТЬЕ. Дата поступления 8 апреля 2016 г.; дата принятия к печати 7 мая 2016 г.; дата онлайн-размещения 31 мая 2016 г.

L. V. Tatarinova Baikal State University, Irkutsk. Russian Federation

\section{ON ISSUE OF CAPITAL SUFFICIENCY OF THE CREDIT ORGANIZATION}

\begin{abstract}
Over the period of the last decades the problem of sustainability of the banking system has been taking form of an international character, which is determined by integration of the banking business. Bankruptcies and financial difficulties in a number of countries because of underestimating the banking activity risks, including the credit risks, have made the representatives of international banking supervision and the Basel Committee prepare the directives capital sufficiency. The article considers approaches of boards of banking supervision and the Basel Committee to changing the constituents of the banking capital items and to the structure of risk balances, implementing active operations by a credit organization. It describes the international experience of determining the credit organizations' capital sufficiency. It generalize the Russian practice of assessing the capital sufficiency Bank of Russia beginning from 1991 and up till now. It analyses the dynamics of own funds (capital) of credit organizations of the Russian Federation and notes the decrease of growth rate of credit organizations' capital and the capital sufficiency standard. An accent is mad on necessity of decreasing active operation risks in the credit organizations for meeting the capital sufficiency standard. KEYWORDS. Own funds (capital) of credit organization; capital sufficiency; the Basel Committee; assets balanced in regard of banking activity risks.
\end{abstract}

ARTICLE INFO. Received April 8, 2016; accepted May 7, 2016; available online May 31, 2016.

() Л. В. Татаринова, 2016

\section{Baikal Research Journal}


Вопросы формирования собственного капитала кредитных организаций, определение его достаточности всегда имели большое значение в российской и международной банковской практике. Величина собственного капитала определяет масштабы деятельности кредитной организации, является ее конкурентным преимуществом. Сами кредитные организации стремятся наращивать собственный капитал, если скорость роста обязательств намного превышает скорость роста ее собственного капитала, а также когда планируется в ближайшем будущем в соответствии со стратегическим планом расширить свою деятельность на рынке банковских услуг. Следует отметить, что сам по себе объем собственного капитала характеризует масштабы банковской деятельности и не дает полной исчерпывающей и точной оценки устойчивости кредитной организации. Для оценки финансовой устойчивости кредитной организации, риска банковской деятельности применяется показатель «достаточность капитала» [1].

В течение длительного времени экономисты, органы банковского надзора и сами кредитные организации разрабатывали подходы к оценке достаточности капитала. Так, Служба контролера денежного обращения США в начале XX в. определяла достаточность капитала кредитных организаций как отношение собственного капитала к депозитам. Минимальный размер данного показателя должен был составлять $10 \%$. Следовательно, кредитная организация в случае массового оттока клиентов (вкладчиков) могла обеспечить собственными средствами десятую часть вкладов. Этот показатель является достаточно простым и по настоящее время используется экономистами при оценке финансового состояния кредитной организации. Основным недостатком данного показателя является то, что он не учитывает риски кредитных организаций при осуществлении банковских операций, а также структуру активных операций. Поэтому с начала 40-х гг. ХХ в. был изменен порядок определения достаточности капитала кредитных организаций. Служба контролера денежного обращения США стала определять достаточность капитала как отношение собственного капитала к активам. Минимальное значение показателя было установлено на уровне $8 \%$. Переход к такому расчету достаточности капитала был обусловлен тем, что состав и качество активов являются одной из главных причин банкротств кредитных организаций [2].

В связи с интеграцией банковского бизнеса в международное банковское сообщество во второй половине 80-х гг. ХХ в. стал вопрос оценки достаточности капитала кредитных организаций. Необходимо было выработать общие международные критерии и правила определения достаточности капитала кредитных организаций, не лишая при этом каждую страну ее специфики и суверенности. В связи с этим Базельский комитет по банковскому надзору в 1988 г. опубликовал документ «Международная конвергенция принципов измерения капитала и стандарты капитала» (его еще называют Соглашение по капиталу, Базель I), который ввел в банковскую практику требования к достаточности капитала [3]. Первоначально данный документ рассматривался как рекомендации, однако с 1992 г. становится обязательной нормой для стран G-10, постепенно к нему присоединяются и другие страны, включая Российскую Федерацию [4].

В документе определены составляющие банковского капитала и структура весов риска, осуществления кредитной организации активных операций. Отметим, что классификация рисков активных операций в документе Базельского комитета была преимущественно ориентирована на ограничение кредитного риска. Говорилось о том, что это основной риск, которому подвержены кредитные организации, это риск дефолта, неплатежеспособности заемщика. Минимальный размер достаточности капитала, его еще называют регулятивным капиталом, был установлен в размере 8 \% от суммы капитала, отнесенной к суммарному объему активов,

\section{Baikal Research Journal}

электронный научный журнал Байкальского государственного университета 
взвешенных с учетом кредитного риска [5]. Размер кредитного риска определялся путем взвешивания величины активов на весовые коэффициенты риска. Активы кредитной организации классифицировались на пять групп с соответствующими весовыми коэффициентами: $0 ; 10 ; 20 ; 50 ; 100 \%$. Чем выше риск активов, тем больше устанавливался весовой коэффициент. В Соглашении по капиталу общая величина собственных средств (капитала) кредитной организации подразделялась на два уровня:

- капитал 1-го порядка - основной капитал, который включал в себя акционерный капитал и объявленные резервы, образованные за счет нераспределенной прибыли;

- капитал 2-го порядка - дополнительный капитал, к которому относили скрытые (непубликуемые) резервы, общие резервы на покрытие убытков будущих периодов, резервы переоценки активов, общие резервы на покрытие убытков по кредитам, сложные финансовые инструменты, долгосрочную субординированную задолженность. В совокупности капитал 2 -го уровня не должен был превышать значение капитала 1-го уровня [2].

Первое Соглашение о капитале Базельского комитета по банковскому надзору оказало положительное влияние на работу кредитных организаций. Требования к достаточности капитала, первоначально разработанные для крупных кредитных организаций, были востребованы органами регулирования и надзора за банковской деятельностью в международной банковской практике. Однако несмотря на новации, введенные Базельским комитетом в области определения достаточности капитала, данное соглашение игнорировало целый ряд банковских рисков (процентный, операционный, страновой риски), уделяя внимание лишь регулированию кредитного риска, кроме того содержало упрощенную градацию кредитного риска для всех крупных заемщиков кредитной организации.

В ноябре 2005 г. Базельский комитет по банковскому надзору опубликовал новый документ «Международная конвергенция принципов измерения капитала и стандарты капитала: новые подходы» (Базель II), который вступил в силу с 1 января 2007 г. Основная его базовая цель - построение основных пруденциальных методов регулирования банковского капитала. Документ вводит новые подходы к оценке принимаемых кредитными организациями рисков и, соответственно, достаточности капитала на их покрытие. Базель II включает в себя следующие основные компоненты [4]:

- минимальные требования к структуре капитала;

- надзорный процесс;

- рыночная дисциплина.

То, что касается компонента «минимальные требования к структуре капитала», то данным документом сохраняется требование к минимальному размеру достаточности капитала (8 \% ), но при этом вместе с кредитным риском начинает учитываться рыночный и операционные риски. Предлагается два базовых подхода к расчету кредитного риска. Первый - стандартизированный подход, при котором степень кредитного риска по активам определяется на основе оценок независимых рейтинговых агентств или надзорных органов. Второй подход основан на внутренних рейтингах, которые сами банки, исходя из накопленной у них информации, составляют с помощью специальных статистических и математических моделей. Базель II предусматривает расширенную трактовку кредитного риска и детализацию заемщиков по их видам (государства, центральные банки, коммерческие банки, индивидуальные заемщики и т. д.) По остальным видам рисков тоже предусмотрены разнообразные опции в зависимости от зрелости банковской системы и наличия соответствующей информации [3].

\section{Baikal Research Journal}

электронный научный журнал Байкальского государственного университета 
В соответствии со вторым компонентом приводятся основные принципы надзорного процесса за кредитными организациями, управление рисками, прозрачность отчетности кредитных организаций. Определены такие понятия, как процентный риск, кредитный риск, операционный риск, секьюритизация активов [6]. Кредитный риск рассматривается с точки зрения стресс-тестирования, определение дефолта заемщика, остаточного риска и риска концентрации кредитов.

Рыночная дисциплина - третий компонент - дополняет минимальные требования к достаточности капитала и надзорный процесс. Рыночная дисциплина кредитных организаций стимулируется путем установления требований к транспорентности (прозрачности) деятельности кредитных организаций [4].

Мировой финансовый кризис 2008 г. показал провалы пруденциального регулирования деятельности кредитных организаций. В 2008-2009 гг. Базельский комитет по банковскому надзору преступил к пересмотру своих требований к достаточности капитала кредитных организаций. Результатом стала система требований к достаточности капитала и ликвидности, получившая название Базель III и одобренная странами G-20 на саммите в Сеуле в ноябре 2010 г. Участники саммита также поддержали переходные периоды для полного внедрения предложений Базель III по капиталу и ликвидности до 2019 г. [7].

Предложения по Базель III имеют две основные цели: укрепить капитал кредитных организаций и повысить ликвидность банковской системы и ее возможности справляться с последствиями финансовых и экономических кризисов [8]. Для достижения этих целей предложения Базель III были разделены на три части по следующим направлениям:

- дополнительные требования к достаточности капитала (включая качество и количество капитала, учет всех рисков, коэффициент долговой нагрузки, ввод понятий «буфер консервации капитала» и «контрциклический капитал»);

- изменение системы оценки рисков ликвидности, стандартов и мониторинга;

- введение других элементов регулирования, относящихся к общему совершенствованию стабильности банковской системы ${ }^{1}$.

Новое Соглашение ужесточает требования к составу капитала 1-го уровня, который включает только обыкновенные акции и нераспределенную прибыль. Капитал 1-го уровня должен быть повышен с 4 до $6 \%$ активов, взвешенных с учетом риска. Акционерный капитал вместе с нераспределенной прибылью должен быть также увеличен с $2 \%$ активов, взвешенных с учетом риска до 4,5\%. Предусматривалось увеличение запасов капитала сверх регулятивного минимума, введение показателя оценки достаточности капитала (соотношение капитала и совокупных активов за вычетом резервов и без учета обеспечения), а также показателей краткосрочной (до 30 дней) и долгосрочной (до одного года) ликвидности [7]. Устанавливаются повышенные нормы на резервный и стабилизационный капитал, который должна иметь каждая кредитная организация. Резервный (буферный) капитал должен составлять 2,5 \% активов кредитной организации. Данный капитал позволит кредитным организациям в случае системного кризиса и снижения норматива достаточности капитала ниже минимально допустимого значения получить дополнительную ликвидность без санкции регулятора. Однако после кризиса кредитные организации обязаны этот капитал восстановить [9]. Появляется понятие не только резервного (буферного) капитала, но и контрциклического капитала [10]. Данный капитал кредитные организации обязаны будут сформировать в случае перегрева экономики, кредитного бума в размере от 0,0 до $2,5 \%$ (табл. 1 ).

${ }^{1}$ Базель III: вопросы внедрения. URL : https://www.kpmg.com/RU/ru/topics/Russian-BankingClub/Documents/Basel\% 20III_rus.pdf.

\section{Baikal Research Journal}

электронный научный журнал Байкальского государственного университета 
Таблица 1

Минимальные требования к составу капитала по требованиям Базель ІІІ в 2013-2019 22., \%

\begin{tabular}{|l|r|r|r|r|r|r|r|}
\hline \multicolumn{1}{|c|}{ Показатель } & \multicolumn{1}{|c|}{2013} & 2014 & \multicolumn{1}{c|}{2015} & \multicolumn{1}{c|}{2016} & \multicolumn{1}{c|}{2017} & \multicolumn{1}{c|}{2018} & \multicolumn{1}{c|}{2019} \\
\hline Акционерный капитал & 3,5 & 4,0 & 4,5 & 4,5 & 4,5 & 4,5 & 4,5 \\
\hline Резервный буфер & - & - & - & 0,6 & 1,2 & 1,8 & 2,5 \\
\hline $\begin{array}{l}\text { Акционерный капитал + резерв- } \\
\text { ный буфер }\end{array}$ & 3,5 & 4,0 & 4,5 & 5,1 & 5,7 & 6,3 & 7,0 \\
\hline Капитал 1-го уровня & 4,5 & 5,5 & 6,0 & 6,0 & 6,0 & 6,0 & 6,0 \\
\hline Достаточность капитала & 8,0 & 8,0 & 8,0 & 8,0 & 8,0 & 8,0 & 8,0 \\
\hline Контрциклический капитал & $0,0-2,5$ & $0,0-2,5$ & $0,0-2,5$ & $0,0-2,5$ & $0,0-2,5$ & $0,0-2,5$ & $0,0-2,5$ \\
\hline
\end{tabular}

Составлено по: Basel Cjmmittee on Banking Supervision. URL : http://www.bis.org/bcbs/publ/ d349.html.

Базель III устанавливает, что в случае несоблюдения нормативов кредитные организации не имеют право выплачивать дивиденды акционерам, а также бонусы и другие премии своим управляющим [11].

Предложенные в Базель III требования к капиталу кредитных организаций являются весьма жесткими и их исполнение поставит многие кредитные организации в непростое положение, но при этом установленный документом срок достаточно большой (до 2019 г.), что даст возможность кредитным организациям увеличить собственные средства (капитал) до необходимого уровня [12].

В российской банковской практике Базельские соглашения стали применяться с 1991 г., когда вышла инструкция Банка России «О порядке регулирования деятельности коммерческих банков» от 30 апреля 1991 г. № 1 (далее -Инструкция № 1). Для обеспечения экономических условий устойчивого функционирования банковской системы РФ в данной инструкции были установлены следующие экономические нормативы деятельности коммерческих банков:

- нормативы достаточности капитала коммерческого банка;

- нормативы ликвидности баланса коммерческого банка;

- минимальный размер обязательных резервов, депонируемых в Банке России;

- максимальный размер риска на одного заемщика.

В соответствии с Инструкцией № 1 достаточность капитала коммерческого банка определялась как соотношение капитала банка и суммарного объема активов, взвешенных с учетом риска $H 1$. Для оценки состояния активов коммерческого банка они подразделялись на шесть групп, исходя из степени риска вложений и возможной потери части стоимости. Минимально допустимое значение норматива $H 1$ устанавливалось на 1991 г. в размере 0,04. Кроме данного показателя достаточность капитала оценивалась как соотношение собственных средств (капитала) и активов с повышенным риском $H 2$. Данный норматив являлся оценочным и рекомендовался коммерческим банкам для расчета при регулировании их активных операций с точки зрения достаточности капитала. Значение норматива $H 2$ коммерческие банки должны были поддерживать на уровне не ниже 0,1. Этот норматив действовал до марта 1995 г.

В отличие от Базельского подхода в Инструкции № 1 при определении рискованности банковских активов был взят не кредитных риск, а риск возникновения просроченной ссудной задолженности. Данный подход к определению степени риска активных операций привел к тому, что у достаточно большого количества кредитных организаций не возникало проблем с выполнением этого норматива, так как активы взвешивалась со значительно меньшим риском. В результате введенный норматив не мог учитывать все риски кредитных организаций при проведении активных операций и оказался неработоспособным.

\section{Baikal Research Journal}

электронный научный журнал Байкальского государственного университета 
В связи с этим Банк России изменяет порядок расчета норматива достаточности капитала, и с 1 марта 1996 г. вышла новая инструкция Банка России «О порядке регулирования деятельности кредитных организаций», в соответствии с которой норматив достаточности капитала $H 1$ определялся как отношение собственных средств (капитала) банка к суммарному объему активов, взвешенных с учетом риска контрагентов. Для оценки состояния активов кредитных организаций они подразделялись на пять групп, исходя из степени риска вложений и возможной потери части стоимости. Минимально допустимое значение норматива $H 1$ устанавливалось в зависимости от размера собственных средств (капитала) кредитной организации (табл. 2).

Таблица 2

\section{Значение норматива достаточности капитала} в российской банковской практике

\begin{tabular}{|c|c|c|}
\hline $\begin{array}{c}\text { Размер собственных средств } \\
\text { (капитала) }\end{array}$ & $\begin{array}{c}\text { Начало действия нормативного } \\
\text { значения }\end{array}$ & $\begin{array}{c}\text { Норматив достаточности } \\
\text { капитала, \% }\end{array}$ \\
\hline \multirow[t]{2}{*}{ От 5 млн ЭКЮ и более } & 1 февраля 1998 г. & 7 \\
\hline & 1 января 1999 г. & 8 \\
\hline \multirow[t]{2}{*}{ От 1 до 5 млн ЭКЮ } & 1 февраля 1998 г. & 7 \\
\hline & 1 января 1999 г. & 8 \\
\hline \multirow[t]{2}{*}{ Менее 1 млн ЭКЮ } & 1 февраля 1998 г. & 7 \\
\hline & 1 января 2000 г. & 11 \\
\hline \multirow[t]{2}{*}{ От 5 млн евро и выше } & 1 февраля 1999 г. & 8 \\
\hline & 1 января 2000 г. & 10 \\
\hline \multirow[t]{2}{*}{ Менее 5 млн евро } & 1 февраля 1999 г. & 9 \\
\hline & 1 января 2000 г. & 11 \\
\hline
\end{tabular}

Составлено по: О порядке регулирования деятельности кредитных организаций : инструкция Банка России от 1 марта 1996 г. № 1-И.

С 1 апреля 2000 г. Банк России изменяет методику расчета норматива $H 1$, характеризующего достаточность капитала. В расчет данного норматива стали включать не только риск контрагентов, но и рыночный риск по отдельным финансовым инструментам. В связи с этим российская банковская практика была приближена к рекомендациям Базельского комитета в области регулирования достаточности капитала.

Банк России отмечает в своих нормативных документах, что норматив достаточности собственных средств (капитала) банка $H 1$ регулирует (ограничивает) риск несостоятельности банка и определяет требования по минимальной величине собственных средств (капитала) банка, необходимых для покрытия кредитного, операционного и рыночного рисков. При определении достаточности капитала стал отдельно выделяться операционный риск, который раньше не учитывался при расчете данного норматива. С выходом новой инструкции Банка России «Об обязательных нормативах банков» от 16 января 2004 г. № 110-И норматив достаточности капитала стал определяться как отношение размера собственных средств (капитала) банка и суммы его активов, взвешенных по уровню риска. В соответствии с данной инструкцией в расчет норматива $H 1$ включаются:

- величина кредитного риска по активам, отраженным на балансовых счетах бухгалтерского учета (активы за вычетом сформированных резервов на возможные потери и резервов на возможные потери по ссудам, по ссудной и приравненной к ней задолженности, взвешенные по уровню риска);

- величина кредитного риска по условным обязательствам кредитного характера;

- величина кредитного риска по срочным сделкам и производным финансовым инструментам;

\section{Baikal Research Journal}

электронный научный журнал Байкальского государственного университета 
- величина операционного риска;

- величина рыночного риска.

Минимально допустимое числовое значение норматива $H 1$ устанавливалось в зависимости от размера собственных средств (капитала) банка: для банков с размером собственных средств (капитала) не менее 180 млн р. - $10 \%$; для банков с размером собственных средств (капитала) менее 180 млн р. - $11 \%$. С 28 апреля 2012 г. минимально допустимое значение норматива достаточности капитала устанавливается Банком России для всех банков в размере $10 \%$.

C целью реализации рекомендаций Базель III по капиталу Банком России в октябре 2013 г. вводятся нормативы достаточности базового капитала, основного капитала и достаточности собственных средств (капитала) банка². Нормативы достаточности капитала банка рассчитываются как отношения величины базового капитала банка, величины основного капитала банка и величины собственных средств (капитала) банка к сумме:

- кредитного риска по активам, отраженным на балансовых счетах бухгалтерского учета (активы за вычетом сформированных резервов на возможные потери и резервов на возможные потери по ссудам, ссудной и приравненной к ней задолженности, взвешенные по уровню риска);

- кредитного риска по условным обязательствам кредитного характера;

- кредитного риска по производным финансовым инструментам;

- величины риска изменения стоимости кредитного требования в результате ухудшения кредитного качества контрагента;

- операционного риска;

- рыночного риска.

Инструкцией были определены минимально допустимое числовое значение норматива базового капитала в размере $5 \%$, а с ноября 2015 г. - 4,5\% ; норматива основного капитала - $5 \%$, а с 1 января 2015 г. - 6,0 \% ; норматива достаточности собственных средств (капитала) банка $-10,0 \%$, а с ноября 2015 г. - $8 \%$.

Предложенный Банком России в соответствии с рекомендациями Базельского комитета расчет достаточности капитала не вызовет трудностей с его исполнением у основной массы кредитных организаций, но у отдельных небольших региональных банков может возникнуть проблема с выполнением данного показателя (табл. 3).

Таблица 3

Диналика собственных средств (капитала) банковского сектора Российской Федерации в 2010-2015 г2. (по состоянию на 1 января)

\begin{tabular}{|c|c|c|c|c|c|c|c|}
\hline Показатель & 01.01 .2010 & 01.01 .2011 & 01.01 .2012 & 01.01 .2013 & 01.01 .2014 & 01.01 .2015 & 01.12 .2015 \\
\hline $\begin{array}{l}\text { Собственные } \\
\text { средства } \\
\text { (капитал), } \\
\text { млрд р. }\end{array}$ & 4621 & 4732 & 5242 & 6113 & 7064 & 7928 & 8891 \\
\hline $\begin{array}{l}\text { Темпы приро- } \\
\text { ста собствен- } \\
\text { ных средств } \\
\text { (капитала), \% }\end{array}$ & - & 2,4 & 10,7 & 16,6 & 15,5 & 12,2 & 12,1 \\
\hline $\begin{array}{l}\text { Норматив } \\
\text { достаточности } \\
\text { капитала, \% }\end{array}$ & 20,9 & 18,1 & 14,7 & 13,7 & 13,5 & 12,5 & 12,9 \\
\hline
\end{tabular}

Составлено по: Отчет о развитии банковского сектора и банковского надзора в 2014 году. URL : http://cbr.ru/publ/archive/root_get_blob.aspx?doc_id=9878.

${ }^{2}$ Об обязательных нормативах банков : инструкция Банка России от 3 дек. 2012 г. № 139-И (в ред. от 1 сент. 2015 г.) // СПС «КонсультантПлюс» .

\section{Baikal Research Journal}


Начиная с 2010 г. норматив достаточности капитала по банковскому сектору Российской Федерации снижается с 20,9 (2009) до 12,9 \% (2015). Снижение было обусловлено замедлением темпов прироста собственных средств (капитала) кредитных организаций Российской Федерации и опережающим ростом активов взвешенных по уровню риска. Особое внимание к соблюдению норматива достаточности капитала должны проявлять те кредитные организации, для которых данный показатель находится на грани или незначительно превышает регламентируемый уровень. Если в 2010 г. девять кредитных организаций не выполняли нормативное значение достаточности капитала, то на 1 января 2015 г. -8 кредитных организаций. В 2010 г. у 20 кредитных организаций норматив достаточности капитала был ниже $12 \%$, а в 2014 г. этот показатель был ниже $12 \%$ уже у 47 кредитных организаций, что составляло 5,6 \% от общего числа зарегистрированных кредитных организаций Российской Федерации. Таким образом, существует опасность, что при реализации определенных финансовых рисков, которые негативно скажутся на уровне собственных средств, эти кредитные организации могут столкнуться с проблемой выполнения норматива достаточности капитала.

Экономисты и представители банковского сообщества предполагают, что внедрение новых стандартов Базеля III в условиях ухудшения делового климата в России может негативно сказаться на деятельности кредитных организаций. Для повышения устойчивости отечественной банковской системы важно не только наращивание собственных средств (капитала) кредитных организаций, но и снижение рисков банковской деятельности.

\section{Список использованной литературы}

1. Татаринова Л. В. Соглашение о капитале: требования Базельского комитета / Л. В. Татаринова, О. А. Соколова // Финансово-кредитная система региона: стратегия и практика : сб. науч. тр. - Иркутск : Изд-во БГУЭП, 2012. — С. 179-183.

2. Гончаров А. И. Международное соглашение «Базель I»: влияние на банковское регулирование в Евросоюзе и России / А. И. Гончаров, М. В. Гончарова // Вестник Волгоградского государственного университета. Сер. 5, Юриспруденция. - 2013. - № 3 (20). - С. 120-129.

3. Козлов А. А. Вопросы реализации Базельских рекомендаций в области банковского надзора в России / А. А. Козлов // Деньги и кредит. - 2006. - № 6. - С. 5-9.

4. Базель II: время действовать / В. Н. Вяткин, В. А. Гамза, М. И. Гуревич, П. В. Калишин // Деньги и кредит. - 2007. - № 9. - С. 41-50.

5. Симановский А. Ю. О регулятивных требованиях к устойчивости банков (развернутые тезисы) / А. Ю. Симановский // Деньги и кредит. - 2009. - № 9. - С. 12-19.

6. Алексеева И. А. Секьюритизация: характерные признаки и определение / И. А. Алексеева, А. Ю. Рачкевич // Деньги и кредит. - 2008. - № 8. - С. 22-32.

7. Кравченко Л. Н. Достаточность собственных средств капитала коммерческих банков в условиях перехода к рекомендациям Базель-ІІІ / Л. Н. Кравченко // Белгородский экономический вестник. -2015 . - № 1 (77). - С. 27-34.

8. Жилан О. Д. Ликвидность коммерческого банка : учеб. пособие / О. Д. Жилан. - Иркутск : Изд-во БГУЭП, 2013. - 107 с.

9. Усоскин В. М. Базель III: влияние на экономический рост (обзор эмпирических исследований) / В. М. Усоскин, В. Ю. Белоусова, М. В. Клинцова // Деньги и кредит. - 2013. № 9. - С. $32-38$.

10. Воловник А. Д. Базель III: испытание надежности банковской системы России в условиях глобальной конкуренции / А. Д. Воловник, Н. С. Зиядуллаев, Ю. С. Кибардина // Экономика мегаполисов и регионов. - 2011. - № 3 (39). - С. 40-49.

11. Кошель Н. В. Формирование и управление банковским капиталом / Н. В. Кошель // Деньги и кредит. - 2010. - № 4. - С. 54-59.

12. Симановский А. Ю. Банковское регулирование: реэволюция / А. Ю. Симановский // Деньги и кредит. - 2014. - № 3. - С. 3-11.

\section{Baikal Research Journal}

электронный научный журнал Байкальского государственного университета 


\section{References}

1. Tatarinova L. V., Sokolova O. A. Agreement on capital: requirements of the Basel Committee. Finansovo-kreditnaya sistema regiona: strategiya i praktika [Regional Finance and Credit System: Strategy and Practice]. Irkutsk, Baikal State University Economics and Law Publ., 2012, pp. 179-183. (In Russian).

2. Goncharov A. I., Goncharova M. V. International agreement "Basel I": influence on banking regulation in European Union and Russia. Vestnik Volgogradskogo gosudarstvennogo universiteta. Seriya 5, Yurisprudentsiya = Scientific Journal of Volgograd State University. Jurisprudence, 2013, no. 3 (20), pp. 120-129. (In Russian).

3. Kozlov A. A. Issues of implementing the Basel recommendations in the field of banking supervision in Russia. Den'gi i kredit = Money and Credit, 2006, no. 6, pp. 5-9. (In Russian).

4. Vyatkin V. N., Gamza V. A., Gurevich M. I., Kalishin P. V. Basel III: time to act. Den'gi $i$ kredit $=$ Money and Credit, 2007, no. 9, pp. 41-50. (In Russian).

5. Simanovsky A. Yu. On regulatory requirements to banks' sustainability (extended proceedings) Den'gi i kredit = Money and Credit, 2009, no. 9, pp. 12-19. (In Russian).

6. Alekseyeva I. A., Rachkevich A. Yu. Securitization: character features and definition. Den'gi $i$ kredit = Money and Credit, 2008, no. 8, pp. 22-32. (In Russian).

7. Alekseyeva I. A., Rachkevich A. Yu. Sufficiency of commercial banks' own funds in terms of transition to Basel III recommendations. Belgorodskii ekonomicheskii vestnik = Belgorod Economic Bulletin, 2015, no. 1 (77), pp. 27-34.

8. Zhilan O. D. Likvidnost' kommercheskogo banka [Commercial bank liquidity]. Irkutsk, Baikal State University Economics and Law Publ., 2013.107 p.

9. Usoskin V. M., Belousova V. Yu., Klintsova M. V. Bazel-III: influence on economic growth (review of empiric investigations). Den'gi $i$ kredit = Money and Credit, 2013, no. 9, pp. 32-38. (In Russian).

10. Volovnik A. D., Ziyadullayev N. S., Kibardina Yu. S. Bazel-III: Test of reliability of bank system Russia in the conditions of a global competition. Ekonomika megapolisov $i$ regionov $=$ Economy of Metropolises and Regions, 2011, no. 3 (39), pp. 40-49. (In Russian).

11. Koshe' N. V. Banking capital formation and regulation. Den'gi $i$ kredit $=$ Money and Credit, 2010, no. 4, pp. 54-59. (In Russian).

12. Simanovsky A. Yu. Banking regulation: reevolution. Den'gi i kredit $=$ Money and Credit, 2014, no. 3, pp. 3-11. (In Russian).

\section{Информация об авторе}

Татаринова Лариса Валентиновна - кандидат экономических наук, доцент, кафедра банковского дела и ценных бумаг, Байкальский государственный университет, 664003, г. Иркутск, ул. Ленина, 11, e-mail: m_credit@isea.ru.

\section{Author}

Larisa V. Tatarnikova - PhD in Economics, Assistant Professor, Chair of Banking and Securities, Baikal State University, 11 Lenin St., 664003, Irkutsk, Russian Federation; e-mail: m_credit@isea.ru.

\section{Библиографическое описание статьи}

Татаринова Л. В. К вопросу о достаточности капитала кредитной организации / Л. В. Татаринова // Baikal Research Journal. - 2016. — T. 7, № 3. — DOI : 10.17150/24116262.2016.7(3).5.

\section{Reference to article}

Tatarinova L. V. On issue of capital sufficiency of the credit organization. Baikal Research Journal, 2016, vol. 7, no. 3. DOI : 10.17150/2411-6262.2016.7(3).5. (In Russian).

\section{Baikal Research Journal}

